\title{
Current Oscillations with Small Amplitudes during Electrocrystallization of Cadmium in the Presence of N,N-Bis (decaoxyethyllene) octadecylamine
}

\author{
Naoyuki SHINOHARA*, Norio KANEKO and Hiroyuki NEZU \\ Received October 31, 1994 ; Accepted January 23, 1995
}

\begin{abstract}
Current oscillations with small amplitudes during the electrocrystallization of cadmium from acidic cadmium sulfate solutions in the presence of $\mathrm{N}, \mathrm{N}$ - bis(decaoxyethylene) octadecylamine (DOOA) were studied by electrochemical methods, electron microscopy and $\mathrm{X}$ - ray diffraction. DOOA adsorbed on the surface of a polycrystalline cadmium cathode inhibited the reduction current of cadmium ion $\left(\mathrm{Cd}^{2}+\right)$ at the potentials more negative than $-0.62 \mathrm{~V}$. The current oscillations with small amplitudes were observed, which depend on experimental conditions (electrolysis potential, concentrations of $\mathrm{Cd}^{2+}$ and DOOA). The upper current density of the oscillations showed the values which were limited by diffusion of $\mathrm{Cd}^{2}+$ with natural convection, and the lower values showed the ones which were inhibited by adsorption of DOOA. Under the conditions that the current oscillations were observed, the aggregates of cadmium crystals grew toward the direction parallel to $(00-1)$ plane of cadmium crystal. The current oscillations with small amplitudes may result from the periodic appearance of new and fresh surfaces of cadmium which is competitive with the coverage of them by DOOA.
\end{abstract}

\section{INTRODUCTION}

Electrochemical oscillations have been observed in a variety of electrochemical systems ${ }^{1,2}$. The current oscillations are observed during the reduction of metal ions on a homogeneous mercury cathode under the fixed circuit potential conditions. These oscillations have been experimentally and theoretically examined ${ }^{3 \sim 8)}$, and recent$1 y$, a general mathematical model which reproduce the current oscillations is suggested 9,10 ).

The authors have investigated the mechanisms of the potential oscillations observed during the galvanostatic electrocrystallization of cadmium, zinc, and tin 11 14). In the case of these investigations, current oscillations with small or large amplitudes could be observed during the potentiostatic electrocrystallization of cadmium from acidic cadmium sulfate solutions on polycrystalline cadmium cathodes in the presence of

Faculty of Engineering, Shinshu University (500 Wakasato, Nagano 380, Japan)

Key word: Current Oscillation, Electrocrystallization of Cadmium, N,N - Bis(decaoxyethylene)octadecylamine
$\mathrm{N}, \mathrm{N}$ - bis (polyoxyethylene)octadecylamine ${ }^{15,16)}$. The mechanism of the current oscillation with large amplitudes and the surface morphology of electrodeposited cadmium was already reported in our previous paper ${ }^{16)}$.

The purpose of this investigation is to study the mechanism of the current oscillations with small amplitudes during electrocrystallization of cadmium in the presence of $\mathrm{N}, \mathrm{N}$ - bis(decaoxyethylene)octadecylamine (DOOA), qualitatively.

\section{EXPERIMENTAL}

\subsection{Apparatus and procedure}

A Hokuto Denko Model HA-310 potentiostat/galvanostat was used in potentiostatic electrocrystallizaion of cadmium. Current - potential curves under potentiostatic conditions were obtained by plotting the steady state current and the amplitudes of current oscillations against the applied potentials. Current-time curves during the potentiostatic electrocrystallization of cadmium were registered using a Toa Electronics Model INR -6012 recorder. All the potentials were re- 
ferred to a saturated calomel electrode (sce). A cell having a volume of $100 \mathrm{~cm}^{3}$ was used and temperature was maintained constant at $25 \pm 1^{\circ} \mathrm{C}$.

The surface morphology of electrodeposited cadmium was observed using a Nihon Denshi Model JSM - 5300 scanning electron microscope and the crystal orientation of electrodeposited cadmium was examined using a Rigaku model RAD - IA X - ray diffractometer.

\subsection{Chemicals and electrode materials}

Sulfuric acid $\left(\mathrm{H}_{2} \mathrm{SO}_{4}\right.$; Wako Pure Chemical Industries, Ltd.), cadmium sulfate $\left(\mathrm{CdSO}_{4}\right.$; Nakarai Tesque Inc.) and $N, N$ - bis(decaoxyethylene)octadecylamine $\left\{\right.$ DOOA; $\mathrm{C}_{18} \mathrm{H}_{37} \mathrm{~N}-$ $\left.\left[\left(\mathrm{CH}_{2} \mathrm{CH}_{2} \mathrm{O}\right)_{10} \mathrm{H}\right]_{2} ; \mathrm{Kao} \mathrm{Co}\right\}$ were of guaranteed reagents. All the reagents were used without further purification and the solutions were prepared in redistilled water.

Cadmium cathode was prepared by electrodeposition of cadmium from an acidic sulfate solution $\left(0.5 \mathrm{M} \mathrm{H}_{2} \mathrm{SO}_{4}+0.4 \mathrm{M} \mathrm{CdSO} 4+0.125 \mathrm{mM}\right.$ DOOA, $M=\mathrm{mol} / \mathrm{dm}^{3}$ ) on a low carbon steel of $7 \mathrm{~cm}^{2}$ surface area (Nissin steel Co. $)^{17}$. Figure 1 shows surface morphology and $\mathrm{X}$ - ray diffraction pattern of an electrodeposited cadmium cathode. A lot of aggregates of plate-like cadmium crystals are observed and two lines with strong intensity, which are assigned to $(00-1)$ crystal

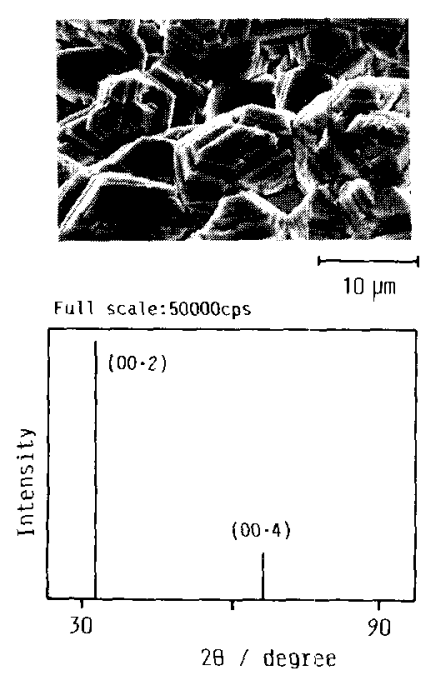

Fig. 1 Surface morphology and $\mathrm{X}$ - ray diffraction pattern of an electrodeposited cadmium cathode. plane of cadmium, are observed on X-ray diffraction pattern. Pure platinum plate of approximate $10 \mathrm{~cm}^{2}$ surface area (Tanaka Kikinzoku Kogyo, Inc; $99.9 \%$ ) was used as the anode.

\section{RESULTS AND DISCUSSION}

\subsection{Current-potential curves}

Figure 2 shows current-potential curves measured in $0.5 \mathrm{M}$ sulfuric acid solutions containing $0.7 \mathrm{M} \mathrm{Cd} 2+$ with and without DOOA using an electrodeposited cadmium cathode (Fig. 1). The vertical lines in Fig. 2 show the amplitudes of current oscillations. The reduction of $\mathrm{Cd}^{2}+$ steeply increased at the more negative potentials than $-0.62 \mathrm{~V}$ in the absence of DOOA (Fig. 2 curve 1 ). In the presence of $5 \mathrm{mM}$ DOOA, the current oscillations with small amplitudes were observed in the range of potentials from -0.75 to $-0.9 \mathrm{~V}$, and the current oscillations with large amplitudes were observed at -0.95 and $-1.0 \mathrm{~V}$ (Fig. 2 curve 2). The current oscillations with small amplitudes are shown in Fig.3. The current oscillations with large amplitudes have been shown in our previous paper ${ }^{16)}$. In an acidic sulfate solution, DOOA becomes a quaternary ammonium ion by adding a proton ${ }^{18)}$ and inhibits the reduction of $\mathrm{Cd}^{2}+$. On an inhomogeneous surface of cadmium

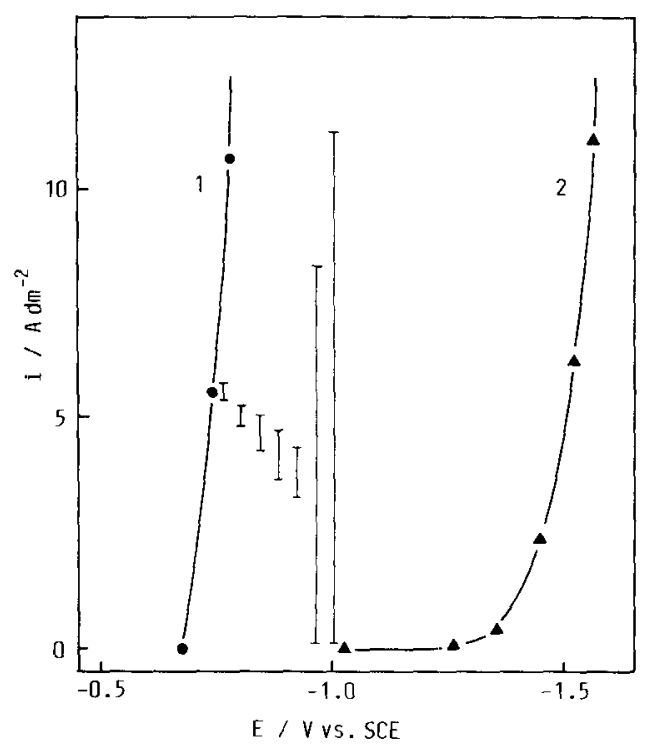

Fig. 2 Current-potential curves for electrodeposited cadmium cathode with and without DOOA. 1) $0.5 \mathrm{M} \mathrm{H}_{2} \mathrm{SO}_{4}+0.7 \mathrm{M} \mathrm{CdSO}_{4}$ 2) 1) $+5 \mathrm{mM} \mathrm{DOOA}$. 
cathode, the inhibitory behavior of DOOA becomes weak as cathode potential is set at more positive potentials because the electrostatic repulsive force between DOOA cations acts more preferentially than the attractive force between DOOA cations and a cathode surface ${ }^{16}$ ). The curve 2 in Fig. 2 might indicate that the oscillations with small amplitudes are observed in the range of potentials in which DOOA cation can not form a compact adsorption layer.

\subsection{Current-time curves}

Figure 3 shows the current-time curves measured at $-0.85 \mathrm{~V}$. The enlarged oscillations are also seen in the figure. The current oscillations with small amplitudes $\left(2.2-3.4 \mathrm{~A} \mathrm{dm}^{-2}\right)$ are observed for the $0.5 \mathrm{M}$ sulfuric acid solutions containing $\mathrm{Cd}^{2}+$ and DOOA (Fig. 3 curves $1-3$ ). The large current $\left(18-21 \mathrm{~A} \mathrm{dm}^{-2}\right)$ due to the reduction of $\mathrm{Cd}^{2}+$ existing in the vicinity of cathode surface are observed at the beginning of each
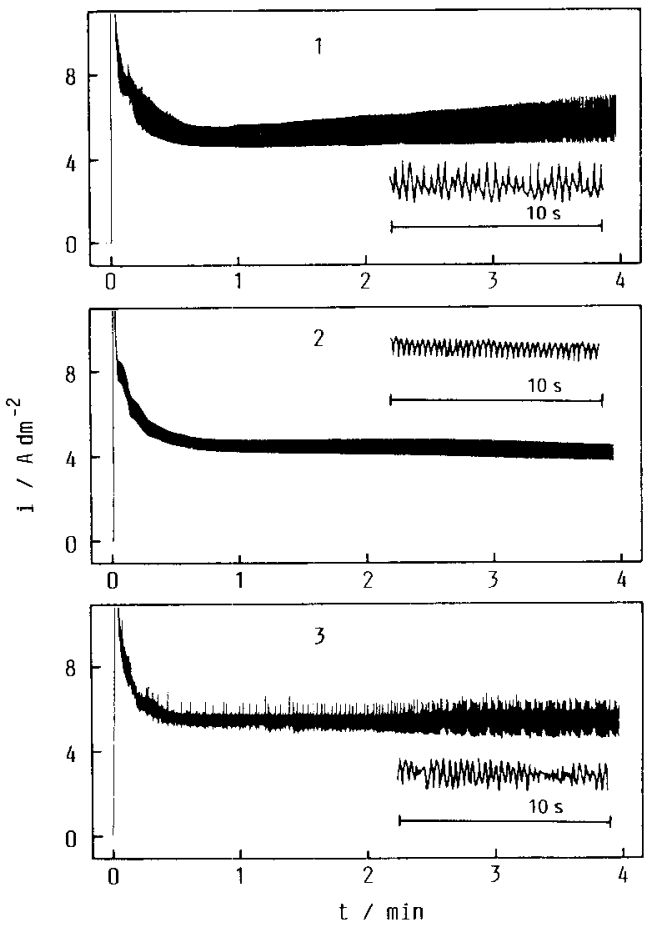

Fig. 3 Current oscillations during potentiostatic electrocrystallization of cadmium.

1) $0.5 \mathrm{M} \mathrm{H}_{2} \mathrm{SO}_{4}+0.7 \mathrm{M} \mathrm{CdSO}_{4}+0.5 \mathrm{mM} \mathrm{DOOA} ;-0.85 \mathrm{~V}$, 2) $0.5 \mathrm{M} \mathrm{H}_{2} \mathrm{SO}_{4}+0.7 \mathrm{M} \mathrm{CdSO}_{4}+5 \mathrm{mM} \mathrm{DOOA} ;-0.85 \mathrm{~V}$, 3) $0.5 \mathrm{M} \mathrm{H}_{2} \mathrm{SO}_{4}+0.9 \mathrm{M} \mathrm{CdSO}_{4}+5 \mathrm{mM} \mathrm{DOOA} ;-0.85 \mathrm{~V}$. electrolysis. Then the current decreased oscillating with small amplitudes, and the current density ranges, in which the oscillation is observed, became nearly constant after about 60 s from the start of each electrolysis.

Figure 4 is the plots of the upper and lower current densities of the oscillations vs. logarithms of concentrations of DOOA and $\mathrm{Cd}^{2+}$. The mean values of upper and lower current densities from 3.8 to $4 \mathrm{~min}$ after the start of electrolyses were plotted in the figure. The upper and lower current densities shifted to lower side and the amplitudes of the oscillations became smaller with increasing concentration of DOOA from $0.25 \mathrm{mM}$ to $1 \mathrm{mM}$. This result suggests that the current density ranges of oscillations shift to lower side and the amplitudes become smaller as the inhibitory behavior of DOOA for the reduction of $\mathrm{Cd}^{2}+$ becomes stronger. Furthermore, the adsorption of DOOA on an inhomogeneous cadmium cathode may be saturated when the bulk concentration of DOOA is higher than $1 \mathrm{mM}$ because the current density ranges and the amplitudes become nearly constant. On the other hand, when

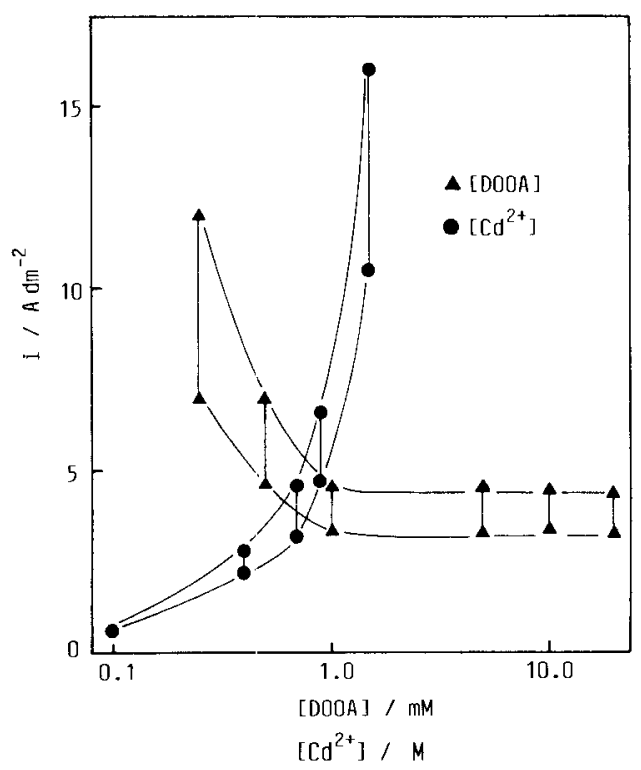

Fig. 4 Plots of upper and lower current densities vs. logarithm of concentration of DOOA and cadmium ion.

(A) $0.5 \mathrm{M} \mathrm{H}_{2} \mathrm{SO}_{4}+0.7 \mathrm{M} \mathrm{CdSO}_{4}+[\mathrm{DOOA}] ;-0.85 \mathrm{~V}$, (O) $0.5 \mathrm{M} \mathrm{H}_{2} \mathrm{SO}_{4}+5 \mathrm{mM} \mathrm{DOOA}+\left[\mathrm{CdSO}_{4}\right] ;-0.85 \mathrm{~V}$. 
the concentration of $\mathrm{Cd}^{2}+$ was varied, the current showed a constant value after ca.30s from the start of each electrolysis in the range of concentrations from 0.02 to $0.1 \mathrm{M}$, and the current oscillations were observed at the concentration of $\mathrm{Cd}^{2+}$ higher than $0.2 \mathrm{M}$. The current density ranges shifted to higher and the amplitudes become larger with increasing concentrations of $\mathrm{Cd}^{2+}$

Figure 5 is logarithmic plot of constant $(\mathbf{O})$, upper (A) and lower. (E) current densities of current-time curves vs. concentration of $\mathrm{Cd}^{2+}$. The constant and the upper current densities were on a straight line with the inclination of 1.21. This result shows the constant and the upper current are proportional to 1.21 power of the bulk concentration of $\mathrm{Cd}^{2+}$. When the mass transport of metal ion from the bulk of solution to the cathode surface is limited by diffusion with natural convection, the electrolytic current is proportional to the 1.25 power of the bulk concentration of metal ion 19,20). Consequently, it is suggested that the upper current densities of the oscillations show the value limited by diffusion of $\mathrm{Cd}^{2}+$ with natural convection. During the decrease in current at the beginning of the oscillation (Fig. $3, \mathrm{t}<60$ s), the diffusion layer of $\mathrm{Cd}^{2+}$

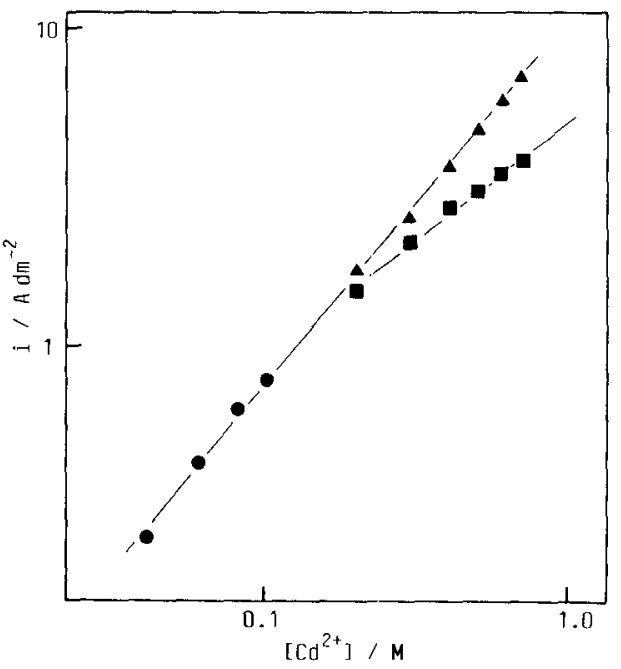

Fig. 5 Logarithmic plots of current density vs. concentration of cadmium ion $\left(0.5 \mathrm{MH}_{2} \mathrm{SO}_{4}+5 \mathrm{mM}\right.$ $\left.\mathrm{DOOA}+\left[\mathrm{CdSO}_{4}\right] ;-0.85 \mathrm{~V}\right)$.

(C) Constant current density, (A) Upper current density, ( $\mathbf{\square}$ ) Lower current density. was formed and its thickness expanded with time. The expansion of diffusion layer was limited by natural convection and its thickness became constant after about 60 s.

The reduction current may oscillate between the diffusion limited current (upper current) and the inhibited current by DOOA (lower current).

\subsection{Growth of aggregates of cadmium crystals}

Figure 6 shows surface morphology observed from the direction perpendicular to the surface and $\mathrm{X}$ - ray diffraction pattern of an electrodeposited cadmium which was obtained under a condition where the current oscillation with small amplitudes was observed. The aggregates of cadmium crystals with a wide base plane were observed on the surface of electrodeposited cadmium. This electrodeposit exhibited (00.2) and $(00.4)$ peaks with very strong intensities, and hence the wide base plane of aggregate was (00.1) plane of cadmium crystal.

Figure 7 shows change in surface and cross sectional morphologies of electrodeposited cadmium with time. The aggregates of plate-like crystals are observed at the surface of electrodeposited cadmium cathode, and triangular shaped elevations are observed in its cross section
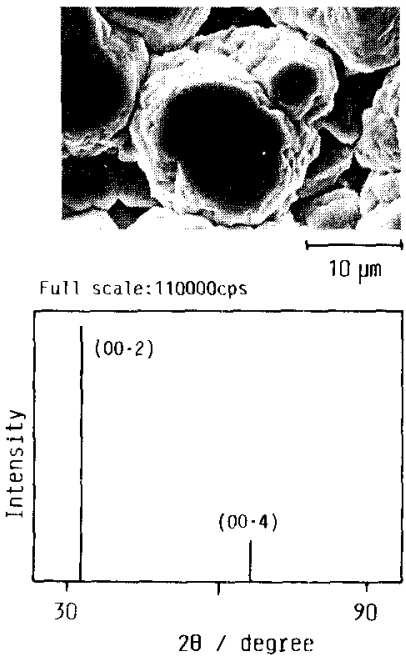

Fig. 6 Surface morphology and X-ray diffraction pattern of electrodeposited cadmium (0.5 $\mathrm{M} \mathrm{H}_{2} \mathrm{SO}_{4}+$ $0.9 \mathrm{M} \mathrm{CdSO}_{4}+5 \mathrm{mM}$ DOOA; $-0.85 \mathrm{~V} ; 4 \mathrm{~min}$ ). 
(Fig.7 photo.1). The number of aggregates decreased and the areas of their base planes expanded with time. Furthermore, the triangular shaped elevations in cross section disappeared and flat planes of $(00 \cdot 1)$ are pronounced (Fig. 7 photo. 2,3). The most thick part of these three deposits were about $25 \mu \mathrm{m}$ independent of electrolysis time. These results show that the aggregates grow toward the direction parallel to $(00 \cdot 1)$ plane and the growth toward the direction perpendicular to $(00 \cdot 1)$ plane is strongly inhibited by DOOA cations adsorbed on its surface.

During the growth of aggregates toward the direction parallel to $(00 \cdot 1)$ plane, new and fresh surfaces of cadmium crystals appear on the side of (00.1) plane. DOOA is supplied from the bulk of solution to the new and fresh surfaces with time delay from the appearance of these surfaces, because the diffusion rate of DOOA is slower than that of $\mathrm{Cd}^{2}+$ as was reported in our previous paper ${ }^{18)}$. Consequently, at the beginning of appearance of the new surfaces, the density of adsorbed DOOA cations on these surfaces is lower than that on the original surfaces where the adsorption of DOOA has reached at an equilibrium. As a result, the current shows an upper value of current oscillation which is limited by

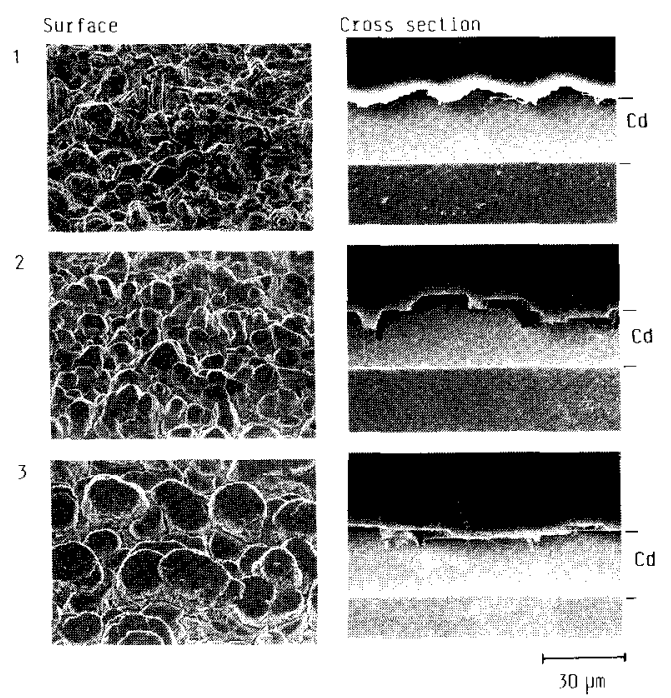

Fig. 7 Change in surface morphology and cross section of electrodeposited cadmium $\left(0.5 \mathrm{M} \mathrm{H}_{2} \mathrm{SO}_{4}+\right.$ $0.7 \mathrm{M} \mathrm{CdSO}_{4}+5 \mathrm{mM} \mathrm{DOOA}^{-}-0.85 \mathrm{~V}$ ).

1) $\mathrm{t}=0,2) \mathrm{t}=120 \mathrm{~s}, 3) \mathrm{t}=420 \mathrm{~s}$. diffusion of $\mathrm{Cd}^{2}+$ with natural convection. Then the current decreases to lower value of current oscillation as a result of the coverage of these new surfaces by DOOA cations diffused from the bulk of solution. However, there are many vacancies in adsorption layer of DOOA cations on the growing surfaces of cadmium crystals, because DOOA cations can not form such a very compact adsorption layer as to inhibit the reduction of $\mathrm{Cd}^{2}+$ almost perfectly owing to the electrostatic repulsive force between them. $\mathrm{Cd}^{2}+$ is reduced at the vacancies and the new and fresh surfaces appear again. Then the current increases to upper value of the oscillation. Such processes are repeated and the current oscillates with small amplitudes and short periods.

The current oscillations on an aggregate are very small, and the synchronization between these minute oscillations would be necessary for being observed as oscillations with large amplitudes which are shown in Fig.3. The detailed examinations of the growth rate of each aggregates and the adsorption behavior of DOOA on aggregates will be necessary for elucidation of the cause of synchrorization. However, it is very difficult to study them precisely on a polycrystalline solid electrode. In this paper, only a qualitative discussion have been made, but a quantitative discussion, especially elucidation of the cause of synchronization, must await a detailed examination about the growth rate of aggregates and the adsorption of DOOA. It will be also necessary to study the adsorption behavior of organic cations such as quaternary ammonium ions or phosphonium ions on single crystal plane of metal.

\section{CONCLUSIONS}

1) Current oscillation with small amplitudes are observed in the range of potentials from -0.75 to $-0.9 \mathrm{~V}$ at which DOOA form a loose adsorption layer owing to the electrostatic repulsive force between DOOA cations.

2) DOOA adsorbed on (00.1) plane of the aggregates of cadrnium crystal inhibits the reduction of $\mathrm{Cd}^{2+}$ and the aggregates grow toward the direction parallel to $(00 \cdot 1)$ plane under 
the condition that the current oscillations are observed.

3) The current oscillations with small amplitudes may result from the periodic appearance of new and fresh surfaces of cadmium which is competitive with the coverage of them by DOOA.

\section{REFERENCES}

1) J.Wojtowicz, "Modern Aspects of Electrochemistry”, ed. by J. O'M. Bockris and B. E. Conway, Vol. 8, Plenum Press, New York, p. 47 (1972).

2) I.Epelboin, C. Gabrielli and M. Keddan, "Comprehensive Treatise of Electrochemistry", ed. by E. Yeager, J. O'M. Bockris, B. E. Conway and S. Sarangapani, Vol. 19, Plenum Press, New York, p. 148 (1984).

3) R. Tamamushi and K. Matsuda, J. Electroanal., Chem., 12, 436 (1966).

4) H. Degn, Trans. Faraday Soc., 64, 1348 (1968).

5) R. DeLevie, J. Electroanal. Chem., 25, 257 (1970).

6) H. Jehring and U. Kuerschner, J. Electroanal. Chem., 75, 799 (1977).

7) J. Keizer and D. Scherson, "J. Phys. Chem., 84,
2025 (1980).

8) H. D. Dörfler and E. Müller, J. Electroanal, Chem., 135, 37 (1982).

9) M. T. M. Koper and J. H. Sluyters, J. Electroanal. Chem., 303, 73 (1991).

10) M. T. M. Koper, Electrochim. Acta, 37, 1771 (1992).

11) H. Nezu, N. Kaneko and N. Shinohara, Denki Kagaku, 54, 173 (1986).

12) N. Kaneko, H. Nezu and N. Shinohara, $J$. Electroanal. Chem., 252, 371 (1988).

13) H. Nezu, N. Shinohara and N. Kaneko, Denki Kagaku, 58, 259 (1990).

14) N. Shinohara, N. Kaneko and H. Nezu, Denki Kagaku, 61, 1211 (1993).

15) N. Shinohara, N. Kaneko and H. Nezu, Bunseki Kagaku, 40, 647 (1991).

16) N. Shinohara, N. Kaneko and H. Nezu, Denki Kagaku, 62, 39 (1994).

17) N. Shinohara, N. Kaneko and H. Nezu, Denki Kagaku, in press.

18) N. Kaneko, N. Shinohara, A. Iizawa and H. Nezu, Denki Kagaku, 60, 434 (1992).

19) C. W. Tobias, M. Eisenberg and C. R. Wilke, J. Electrochem. Soc., 99, 359C (1952).

20) O. Kardos and D. G. Foulke, "Advances in Electrochemistry and Electrochemical Engineering", ed. by C. W. Tobias, Vol. 2, Interscience Publishers, New York, p.145 (1962). 